\title{
Grisel's syndrome presenting with neck pain: an atypical case
}

\author{
Emre Bilgin ${ }^{\circledR}$ Gökhan Çavuş, Vedat Açık, Yurdal Gezercan, Ali İhsan Ökten \\ Department of Neurosurgery, Adana City Training and Research Hospital, Adana, Turkey.
}

\begin{abstract}
Grisel's syndrome is non-traumatic inflammatory subluxation of the atlantoaxial joints presenting clinically as torticollis, neck pain, and reduced neck mobility. Several pathogens have been implicated in its etiology. Early diagnosis and treatment are vital for Grisel's syndrome to avoid serious neurological complications. This study reports the case of a 6-year-old girl who complained of pain and curvature of the neck following an upper respiratory tract influenza infection. Notably, the patient's neck pain and curvature worsened toward the end of her normal day for a week. This pattern is rare, but it represents an important example of Grisel's syndrome as a condition that varies through the day.
\end{abstract}

Key words: atlantoaxial joints, torticollis, viral infection, pain.

Grisel's syndrome is non-traumatic inflammatory subluxation of the atlantoaxial joints; it presents clinically as torticollis and neck pain, and a decrease in neck mobility is observed, with surgical interventions showing hyperlaxity of the alar and transverse ligaments of atlantoaxial joints. The condition is diagnosed by clinical and neuroradiological examinations and can be cured completely via medical means. Several pathogens, including the Epstein-Barr virus, Streptococcus pyogenes, and Staphylococcus aureus, and Kawasaki disease have been implicated in its etiology. Early diagnosis and treatment are vital for patients with Grisel's syndrome as it can cause serious neurological complications if left untreated.

Here, we present the case of a 6-year old girl who complained of pain and curvature of the neck following an upper respiratory tract influenza infection. She had no history of trauma. For a week, the patient's neck pain and curvature had worsened toward the end of each day. This pattern is rare, but it represents an important

$凶$ Emre Bilgin

dremreblgn@gmail.com

Received 4th December 2018; revised 26th Januray 2019, 7th February 2019; accepted 14th February 2019 example of Grisel's syndrome as a condition that varies through the day.

\section{Case Report}

A young 6-year-old girl was brought to the Neurosurgery outpatient clinic complaining of pain and curvature of the neck, which she had been experiencing since a week. Her parents explained that the girl's neck mobility was normal after waking up in the morning, with the curvature and pain in the neck area increasing progressively through the day (Fig. 1). The pain and limited neck mobility were associated with clinical torticollis.

The neck-related problems began following influenza-like symptoms, such as fever and nasal discharge, which started two weeks prior to presentation. Specific blood infection parameters included a sedimentation rate of $38 \mathrm{~mm} / \mathrm{h}$, a C-reactive protein level of 74.30 $\mathrm{mg} / \mathrm{L}$, and a white blood cell count of $12.6 \times 10^{3}$ cells $/ \mathrm{mm}^{3}$. Reproduction was not observed in any of the body fluid samples sent for culture. Under microscopy, the blood peripheral smear revealed atypical cells (Downey cells), which were considered to have developed secondary to the viral infection. 


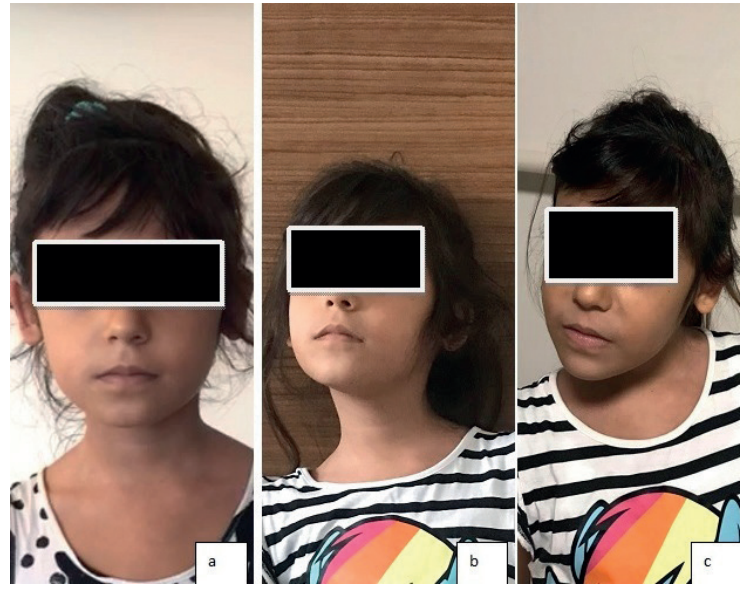

Fig. 1. The case's torticollis that intensified through the day (a-6:00 in the morning, b-12:00 midday, $\mathrm{c}-22: 00$ in the evening)

Three-dimensional (3D) reformatted cervical computed tomography $(\mathrm{CT})$ revealed narrowing at the right anterior of the atlantoaxial joint range on cervical $1(\mathrm{C} 1)$ and cervical 2 (C2), and image matching with subluxation was detected (Fig. 2). Because the patient did not experience torticollis in the early hours of the morning and there was only a small amount of pain at this time, a further 3D reformatted cervical CT scan was performed at 06:00 AM. This revealed that the atlantoaxial distance was normal and that the subluxation had been repaired (Fig. 3).

Superficial neck ultrasonography revealed multiple reactive, ovoid-shaped lymph nodes within the submandibular area on both cervical chains; one on the right was $23 \mathrm{~mm}$ long and one on the left was $17 \mathrm{~mm}$ long. Contrastenhanced cervical magnetic resonance imaging (MRI) showed bilateral submandibular reactive lymph nodes and signal variations related to infection inflammation. These exhibited intense contrast and did not form distinct boundaries, and which hold the paravertebral tissues through $\mathrm{C} 1$ and $\mathrm{C} 2$ vertebrae toward inferior on nasopharynx left lateral wall, have been imaged (Fig. 4).

On the basis of these findings, Grisel's syndrome was diagnosed and the patient was administered an appropriate antibiotic treatment (ceftriaxone $2 \times 50 \mathrm{mg} / \mathrm{kg}$ and clindamycin $3 \times 40 \mathrm{mg} / \mathrm{kg}$

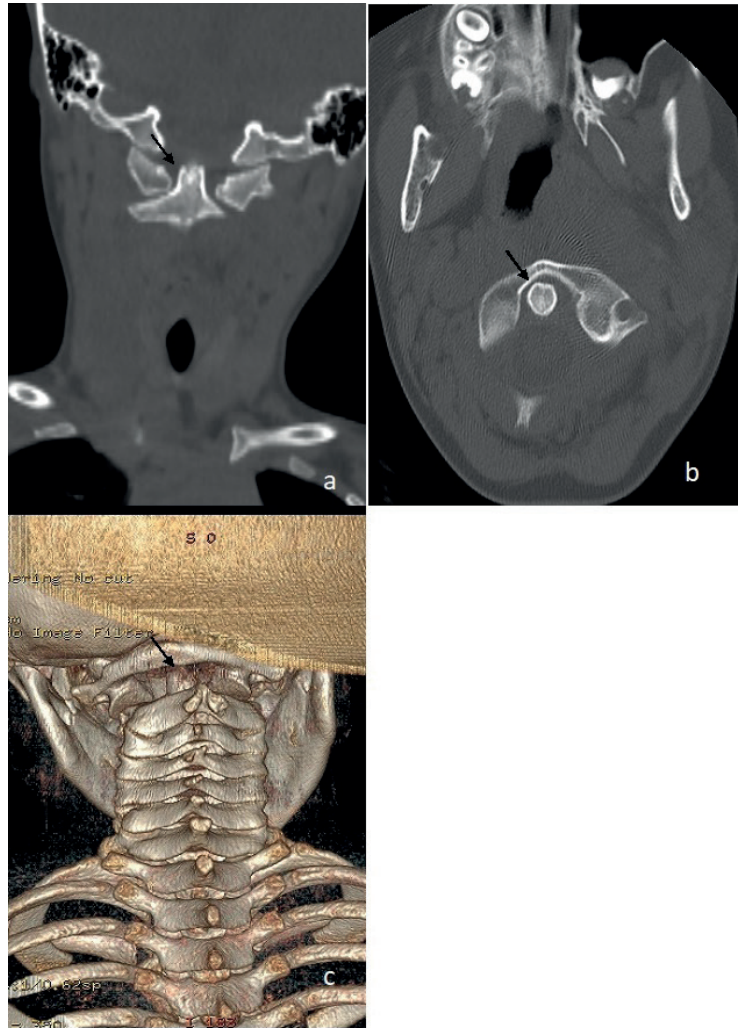

Fig. 2. Narrowing and image matching with subluxation at right anterior of atlanto-axial joint range in coronal (a) axial (b) section and reformat 3D cervical (c) CT images (black arrows)

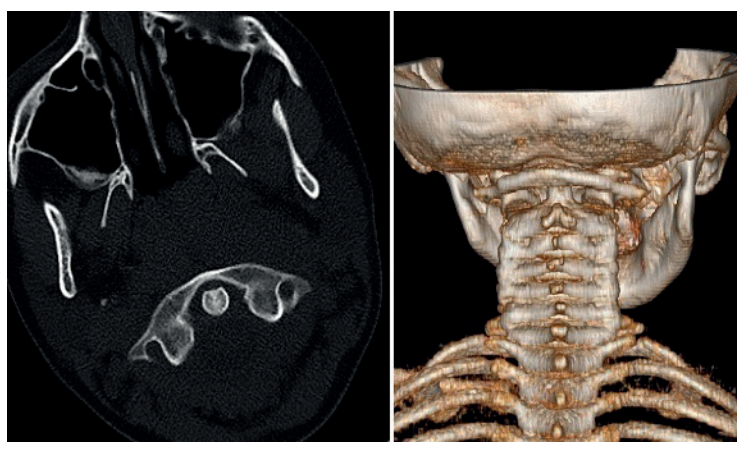

Fig. 3. It is observed that the atlanto-axial distance is normal and subluxation is non-existent in the axial section (a) and reformat 3D (b) cervical CT images.

intravenously, and ibuprofen syrup $4 \times 20$ $\mathrm{mg} / \mathrm{kg}$ cups orally). Following two weeks of treatment, clinical, laboratory, and radiological findings showed the patient had recovered, and she was discharged home. During the two weeks after discharge, the patient was 

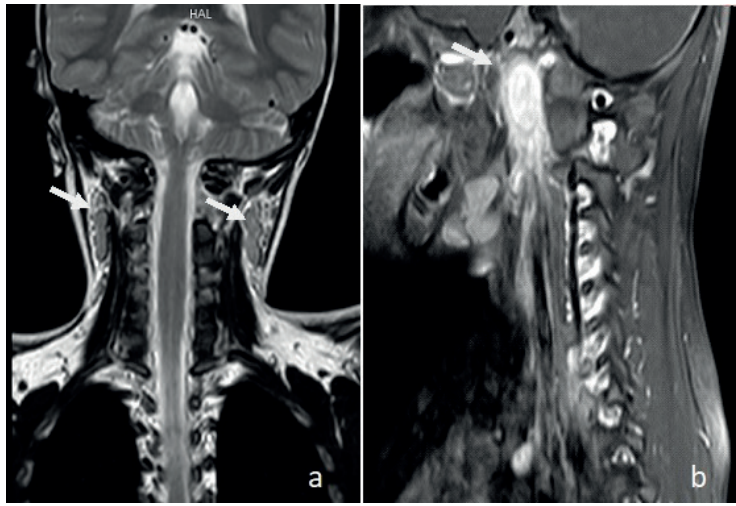

Fig. 4. Fusiform shaped lymph nodes with think cortexes on the bilateral submandibular area in contrast enhanced cervical MRI coronal (a) and sagittal (b) sections (white arrows), and soft tissue inflammation showing the substance retention in the parapharyngeal area, can be observed (white arrow.

mobilized with a cervical corset. Follow-up examinations at the outpatient clinic one month after discharge detected no pathology and there was no dislocation in the control CT (Fig. 5).

The child's parents provided written informed consent for the publication of this case report.

\section{Discussion}

Grisel's syndrome is characterized by rotator subluxation of the atlantoaxial junction of the first and second cervical spines (C1 and $\mathrm{C} 2$ ). It is non-traumatic and rare, appearing after an inflammatory process. ${ }^{1-3}$ Grisel's syndrome has been reported after otorhinolaryngology infections, ${ }^{4-6}$ or with osseous, ocular, ligamentous, psychiatric, and neurological disorders after head and neck surgery. ${ }^{7}$ In addition, torticollis in childhood can be associated with infective agents. ${ }^{8}$ The syndrome can be caused by various infectious agents, including Streptococcus pyogenes, Bacteroides ureolyticus, ${ }^{9} \quad$ Mycobacterium tuberculosis, ${ }^{10}$ Pseudomonas aeruginosa, Staphylococcus aureus, methicillin-resistant Staphylococcus epidermidis, the Epstein-Barr virus, and Kawasaki disease. ${ }^{11,12}$ In our case study, it was concluded that Grisel's syndrome developed secondary to the patient's recent upper respiratory tract viral infection.

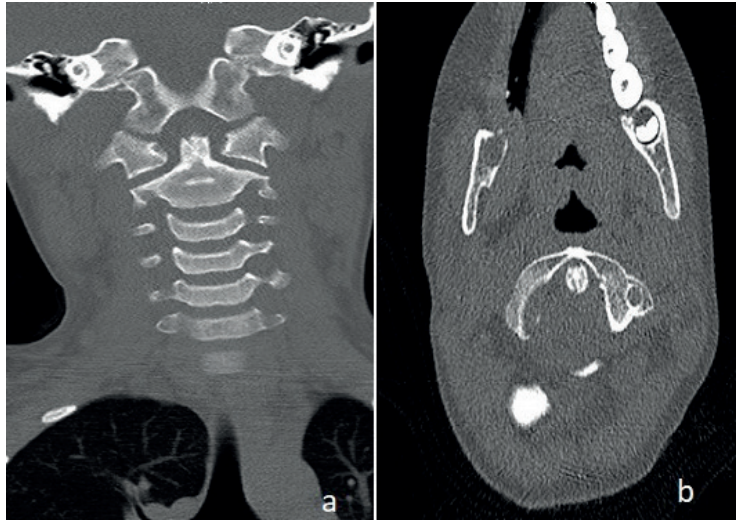

Fig. 5. It is observed that there are no subluxation and the ordinary atlanto-axial joint distance is normal in the cervical CT images in coronal (a) axial (b) sections.

No microorganisms could be reproduced in the blood or urine cultures, and there were atypical lymphocytes in the peripheral blood smear that supported the occurrence of such a viral infection.

Grisel's syndrome, which is generally accompanied by torticollis, presents with curvature of the neck, pain in the neck, and limited neck mobility. ${ }^{13,14}$ The torticollis appears very soon after the start of a head and neck infection or following infection of the otorhinolaryngological tracts. ${ }^{15}$ Unusually, the patient in our case study did not experience torticollis when she woke in the morning, but the torticollis intensified toward the evening. This pattern has been rarely seen in the literature. In addition, there have been no previous reports of radiology findings that show the absence of subluxation in the morning but its presence later in the day, accompanying the torticollis.

Theearly diagnosis of Grisel's syndromeis of vital importance. Serious neurological complications can occur if the condition goes unnoticed or is improperly treated. The condition is diagnosed radiologically using radiographs, $\mathrm{CT}$, and MRI to show atlantoaxial subluxation. It is difficult to diagnose with radiographs alone. ${ }^{16}$ The best modality for diagnosing atlantoaxial subluxation is CT, with $3 \mathrm{D}$ CT providing the optimal view of this pathology. MRI may show abnormalities in the soft tissue and 
nervous tissue that are complementary to the radiological examination. ${ }^{17}$ These examinations were utilized during the clinical management of the present case.

When Grisel's syndrome is diagnosed early, the primary treatment is conservative. Laboratory tests are required for the early diagnosis and to establish the etiology, and antibiotic treatment, bed rest, external fixation, anti-inflammatory drugs, and muscle relaxants are used against the active infectious agent; plasma exchange or immunoglobulin treatment must be started promptly in cases with a resistant form of infectious agent. ${ }^{18}$ Treatment selection for the atlantoaxial joint subluxation depends on the severity of the injury. In non-serious injuries, physiotherapy and manipulation may be used; open surgery is indicated for serious subluxations. ${ }^{19}$ According to the classification of subluxations of the atlantoaxial joint of Fielding and Hawkins ${ }^{20}$ (Table I), types 1 and 2 represent the most common groups with no neurological deficiency, and types 3 and 4 are the groups that may lead to serious neurological deficiencies associated with spinal cord compression. The subluxations of the atlantoaxial joint were type 1 according to the Fielding classification in our case study.
Antibiotics, muscle relaxants, anti-inflammatory drugs, physiotherapy, and soft cervical corsets are recommended for the treatment of patients with type 1 subluxation. More-invasive methods, such as a halo vest, are included if neurological deficiency starts. In the most severe cases with repetitive subluxation, or in cases with difficult reduction, occiput $(\mathrm{CO}) \mathrm{CO}$ C1-C2 arthrodesis may be applied on the C1C2 posterior arthrodesis line. ${ }^{19}$ In the present case, we started treatment using antibiotics, muscle relaxants, and anti-inflammatory drugs, and then applied immobilization with a cervical corset.

Grisel's syndrome should be included in the differential diagnosis for malformation of the occipital, atlas, and axis bones that affect the craniocervical joint, and foramen magnum malformations. Atlantoaxial instability, infections, trauma, inflammation, malignancy, and Sandifer syndrome ${ }^{21,22}$ should be ended as atlantoaxial instability like Grisel's syndrome.

In conclusion, Grisel's syndrome should be kept in mind for pediatric cases with neck pain and torticollis following a recent upper respiratory tract infection. Painful torticollis that shows a fatal course in the morning and intensifies

Table I. Fielding and hawking classification, reported in $1977 .{ }^{20}$

\begin{tabular}{|c|c|c|}
\hline Type 1 & $\begin{array}{l}\text { Most common and is characterized by a simple } \\
\text { rotation without anterior displacement of the atlas } \\
\text { and the transverse ligament is undamaged }\end{array}$ & $\begin{array}{l}\text { Antibiotics, muscle relaxant, massage therapy, } \\
\text { and immobilization with a soft collar }\end{array}$ \\
\hline Type 2 & $\begin{array}{l}\text { The rotatory subluxation is associated with } \\
\text { anterior displacement of the atlas } \leq 5 \mathrm{~mm} \text { and } \\
\text { transverse ligament deficit }\end{array}$ & $\begin{array}{l}\text { Reduction and cervical traction with a rigid } \\
\text { collar }\end{array}$ \\
\hline Type 3 & $\begin{array}{l}\text { Anterior displacement of the atlas is }>5 \mathrm{~mm} \text {, } \\
\text { both lateral atlantoaxial joints are subluxated } \\
\text { anteriorly, the transverse ligament and the } \\
\text { articular facets are damaged }\end{array}$ & $\begin{array}{l}\text { Both type } 3 \text { and } 4 \text { subluxation are highly } \\
\text { unstable lesions and, in most cases, associated } \\
\text { with neurological symptom. It is necessary } \\
\text { cervical traction with "halo vest" and, in the } \\
\text { event of neurological symptoms, decompression } \\
\text { and arthrodesis of C1 C2 }\end{array}$ \\
\hline Type 4 & $\begin{array}{l}\text { Quite rare, more frequent in adults with } \\
\text { rheumatoid arthritis characterized by rotation and } \\
\text { posterior dislocation of atlas }\end{array}$ & $\begin{array}{l}\text { Both type } 3 \text { and } 4 \text { subluxation are highly } \\
\text { unstable lesions and, in most cases, associated } \\
\text { with neurological symptom. It is necessary } \\
\text { cervical traction with "halo vest" and, in the } \\
\text { event of neurological symptoms, decompression } \\
\text { and arthrodesis of C1 C2 }\end{array}$ \\
\hline
\end{tabular}


toward the evening may also indicate Grisel's syndrome. Progressive neurological deficit and permanent neck deformity can be prevented with appropriate and prompt medical treatment.

\section{REFERENCES}

1. Grisel P. Enucleation de l'atlas et torticollis nasopharyngien. Presse Med 1930; 38: 50-54.

2. Pilge H, Prodinger PM, Bürklein D, Holzapfel BM, Lauen J. Nontraumatic subluxation of the atlantoaxial joint as rare form of acquired torticollis: diagnosis and clinical features of the Grisel's syndrome. Spine (Phila Pa) 2011; 36: E747-E751.

3. Rinaldo A, Mondin V, Suárez C, Genden EM, Ferlito A. Grisel's syndrome in head and neck practice. Oral Oncol 2005; 41: 966-970.

4. Elyajouri A, Assermouh A, Abilkacem R, Agadr A, Mahraoui C. Grisel's syndrome: a rare complication following traditional uvulectomy. Pan Afr Med J 2015; 20: 62 .

5. Coca-Pelaz A, Vivanco-Allende A, Meilán-Martínez Á, Gómez-Martínez JR. Grisel's syndrome as a sequela of a complicated acute mastoiditis. Acta Otorrinolaringol Esp 2013; 64: 161-164.

6. Cekinmez M, Tufan K, Sen O, Caner H. Nontraumatic atlanto-axial subluxation: Grisel's syndrome. Two cases reports. Neurol Med Chir (Tokyo) 2009; 49: 172-174.

7. Karkos PD, Benton J, Leong SC, Mushi E, Sivaji $\mathrm{N}$, Assimakopoulos DA. Grisel's syndrome in otolaryngology: a systematic review. Int J Pediatr Otorhinolaryngol 2007; 71: 1823-1827.

8. Per H, Canpolat M, Tümtürk A, et al. Different etiologies of acquired torticollis in childhood. Childs Nerv Syst 2014; 30: 431-440.

9. Wieringa JW, Wolfs TFW, van Houten MA. Grisel syndrome following meningitis and anaerobic bacteremia with bacteroides ureolyticus. Pediatr Infect Dis J 2007; 26: 970-971.

10. Lee JK, Oh CH, Park HC, Yoon SH. Grisel's syndrome induced by Mycobacterium tuberculosis. Korean J Spine 2015; 12: 84-87.
11. Nozaki F, Kusunoki T, Tomoda Y, et al. Grisel syndrome as a complication of Kawasaki disease: a case report and review of the literature. Eur J Pediatr 2013; 172: 119-121.

12. Wood AJ, Singh-Grewal D, De S, Gunasekera H. Kawasaki disease complicated by subluxation of cervical vertebrae (Grisels syndrome). Med J Aust 2013; 199: 494-496.

13. Martinez-Lage JF, Martinez Perez M, Fernandez Cornejo VJ, Poza M. Atlanto-axial rotatory subluxation in children: early management. Acta Neurochir (Wien) 2001; 143: 1223-1228.

14. Martinez-Lage JF, Torres Tortosa P, Piqueras Perez C. Trauma to the spine and spinal cord in children and adolescents. In: Villarejo F, Martinez-Lage JF (eds). Neuorocirugia Pediatrica. Madrid: Ergon, 2001: 221-239.

15. Bocciolini C, Dall'Olio D, Cunsolo E, Cavazzuti PP, Laudadio P. Grisel's syndrome: a rare complication following adenoidectomy. Acta Otorhinolaryngol 2005; 25: 245-249.

16. Lennarson PJ, Traynelis VC, Menezes AH Degenerative and rheumatological diseases of the occipitocervical junction. In: Sekhar LN, Fesler RG (eds). Atlas of Neurosurgical Techniques: Spine and Peripheral Nerves. New York: Thieme, 2006: 13-22.

17. Li V, Pang D. Atlanto-axial rotatory fixation. In: Pang D (ed). Disorders of the Pediatric Spine. New York: Raven 1995: 531-553.

18. Yimenicioğlu S, Yakut A, Ekici A, Carman KB, Dinleyici EC. Mycoplasma Pneumoniae infection with neurologic complications. Iran J Pediatr 2014; 24: 647-651.

19. Beier AD, Vachhrajani S, Bayerl SH, Aguilar CYD, Lamberti-Pasculli M, Drake JM. Rotatory subluxation: experience from the hospital for sick children. J Neurosurg Pediatr 2012; 9: 144-148.

20. Fielding JW, Hawkins RJ. Atlanto-axial rotatory fixation (fixed rotatory subluxation of the atlantoaxial joint). J Bone Joint Surg Am 1977; 59: 37-44.

21. Czinn SJ, Blanchard S. Gastroesophageal reflux disease in neonates and infants: when and how to treat. Paediatr Drugs 2013; 15: 19-27.

22. Cafarotti A, Bascietto C, Salvatore R, Breda L, Chiarelli F, Piernicola P. A 6-month-old boy with uncontrollable dystonic posture of the neck. Sandifer syndrome. Pediatr Ann 2014; 43: 17-19. 